\title{
DEPENDÊNCIA ECONÔMICA E VULNERABILIDADE EXTERNA REGIONAL DO ESTADO DO PARÁ EM PERÍODO RECENTE
}

\author{
Nathálya Rocha de Sousa1 \\ José Raimundo Trindade ${ }^{2}$
}

\section{INTRODUÇÃO}

O Brasil realizou um significativo processo de liberalização cambial-financeira na década de 1990, seguindo um regramento internacional centrado no "status quo" do assim denominado "Consenso de Washington"3. Essa política trouxe como resultado apreciação cambial e maior exposição externa da economia nacional, reforçada em grande parte, pelo processo de globalização financeira. Isto fez com que o Brasil aprofundasse a vulnerabilidade externa da sua economia e enfraquecesse os elos industriais mais organizados, ao mesmo tempo em que gerou a necessidade de superávits primários baseados em maior exportação de produtos básicos, como minerais e commodities agrícolas.

No final do século XX o estado do Pará assume, no bojo da estrutura econômica brasileira, o papel de Estado produtor e exportador de bens primários, gerador de divisas externas necessárias ao equilíbrio do balanço de pagamentos nacional. Nesse período, o dinamismo da economia paraense encontra-se centrado na exportação quase que exclusiva de um conjunto de produtos de origem extrativa mineral, baseado pela presença em seu território de diversos empreendimentos capitalistas de grande porte, intensivos em capital, objetivando basicamente a extração e beneficiamento mineral, sendo sua produção destinada exclusivamente para abastecer o mercado internacional, de acordo com a política de desenvolvimento planejada para a economia nacional.

A partir da integração da sua economia à estratégia de desenvolvimento nacional, o Estado do Pará passou a se especializar na produção e exportação de produtos minerais, de alta intensidade de capital, e de produtos agroindustriais, voltados para o atendimento do mercado internacional.

\footnotetext{
1 Mestre em Economia pelo Programa de Pós-graduação em Economia (PPGE/UFPa).

2 Doutor em Desenvolvimento Econômico e Professor e pesquisador associado ao Programa de Pós-graduação em Economia (PPGE/UFPa).

3 Termo usado por Williamson (1990), que de forma geral significou um conjunto de diretrizes desenvolvidas no âmbito do BIRD, FMI, direcionadas a diversos países e regiões, em destaque a América Latina. Williamson (1990) enumera dez medidas contidas no consenso de Washington: 1) Disciplina fiscal; 2)Mudanças nas Prioridades das Despesas Públicas; 3)Reforma Tributária; 4)Taxas de juros positivas; 5) Taxas de Câmbio determinadas pelo mercado; 6) Abertura Comercial; 7) Investimento Direto Estrangeiro; 8) Privatizações de Empresas Públicas; 9) Desregulamentação das atividades Econômicas; 10) Aplicação de Direito de Propriedade. Ver Williamson, 1990.
} 
Considerando o quadro geral acima exposto, faz-se o seguinte questionamento: Como as alterações na economia brasileira na década de 1990 condicionaram a economia paraense e se é possível afirmar que houve o agravamento do grau de vulnerabilidade econômica do Estado do Pará, em face do quadro de elevada presença do setor em sua estrutura produtiva?

Vulnerabilidade externa, segundo Gonçalves $(2005$, p.19) é a baixa capacidade de resistência das economias nacionais a choques e desequilíbrios externos. Nesse sentido, uma economia reduz sua capacidade de resistência frente a fatores externos quando possui elevada dependência de capitais estrangeiros ou fluxos econômicos sob pequena capacidade de controle local, ou fragilidade financeira externa, como foi o caso da economia brasileira, na década de 1990 e primeira metade da década de 2000 , caracterizada por ser uma economia semiperiférica e em desenvolvimento. No caso do Estado do Pará, vale indagar quanto as consequências que a concentração da base econômica extrativa-mineral produziu, inclusive nos valendo da construção de indicadores de vulnerabilidade econômica regional.

A crescente integração da economia paraense à estratégia de desenvolvimento nacional centrada em superávits da balança comercial estabeleceu uma forte especialização na produção e exportação de produtos minerais, de alta intensidade de capital, e de produtos agroindustriais, voltados para 0 atendimento do mercado internacional.

A transformação da estrutura econômica paraense não se restringiu, todavia, aos projetos de extração e beneficiamento mineral. Ao contrário, além desses foram implantados inúmeros projetos agroindustriais, agropecuários e madeireiros. Com a implantação e funcionamento desses empreendimentos produtivos, a economia do Pará passou a apresentar um perfil produtivo centrado no setor mineral, transitando do status de economia exportadora tradicional de produtos primários oriundos do setor extrativo vegetal, e passou a se comportar como economia exportadora de produtos principalmente de origem extrativo mineral. Antes de sofrer essa transformação, os principais produtos exportados ainda eram considerados básicos, sem beneficiamento industrial como: madeira, pimenta-do-reino, castanha, camarão e peixe, até a década de 70. A partir daí, com o início da produção de bauxita, celulose, minério de ferro, manganês, alumínio, alumina e outros, a pauta de exportação referente aos produtos considerados como básicos passou a ser dominado pelo minério de manganês, minério de ferro, caulim e bauxita, enquanto que como semimanufaturados passou a imperar a exportação de alumínio, alumina, celulose, ferro-gusa silício e cobre.

É importante ressaltar que devido às características dos projetos instalados, metade dos produtos de origem mineral é considerada básica, sem beneficiamento industrial, enquanto que, apesar de perceber um mínimo de beneficiamento industrial, a outra metade é classificada como 
produtos semimanufaturados. Com isso, é possível notar que o Estado do Pará mudou o perfil da sua produção, mas sem se desvencilhar de sua principal característica: exportador de matériasprimas.

Consequentemente, este novo perfil produtivo contribuiu e ressaltou a situação apresentada pela balança comercial do Estado, uma vez que, quase toda a produção é voltada ao beneficiamento de minérios e outros produtos relevantes que são exportados para o mercado externo, e ainda por uma pequena parcela de produtos oriundos da importação. Isto contribuiu para que o saldo da balança comercial do Pará venha apresentando superávits, de forma permanente e crescente.

Este artigo tem como objetivo principal analisar a especifica inserção da economia paraense no padrão produtivo nacional, buscando utilizar para isso índices de vulnerabilidade econômica regional comparativa entre as unidades federativas. Para tratar do padrão produtivo nacional e sua relação com a economia regional lança-se mão do aporte teórico da dependência (Teoria da Dependência), combinado a elementos da chamada Economia Política Internacional (EPI), especialmente os condicionantes que produzem maior ou menor grau de vulnerabilidade externa de uma economia. A construção de indicadores de vulnerabilidade regional se baseou em metodologia homônima referente a vulnerabilidade externa para países desenvolvido por Gonçalves (2005), com adaptações para o contexto regional, conforme será apresentada na devida seção deste trabalho.

O artigo, além desta introdução, apresenta quatro seções expositivas, na primeira seção apresenta-se o entendimento das condições de desenvolvimento desigual na economia brasileira, tratada a partir do aporte teórico da dependência; na segunda seção trata-se do que aqui denominamos de desenvolvimento dependente regional, expondo também a construção de índices de vulnerabilidade aplicáveis as relações periféricas nacionais; na terceira seção trata-se dos índices comparativos e demonstra-se às condições de vulnerabilidade das economias estaduais e especificamente analisa-se o caso do estado do Pará; por fim faz-se as considerações finais. 


\section{O APORTE DA DEPENDÊNCIA E AS CONDIÇÕES DE DESENVOLVIMENTO DESIGUAL NO BRASIL}

A Teoria da Dependência (TD) surgiu em meados da década de 19604, em parte como uma reação ao aparente fracasso da análise e das propostas dos desenvolvimentistas e em grande medida como tentativa de explicar as novas características do desenvolvimento socioeconômico da região. Os teóricos da dependência argumentavam que a estratégia de industrialização baseada na substituição das importações era incapaz de produzir efeitos de ruptura com 0 subdesenvolvimento, pois o mesmo seria antes de tudo uma consequência e parte do processo de expansão mundial do capitalismo (DOS SANTOS 1970; 2015; GILPIN, 2002; KAY, 1989).

A relação de interdependência entre ou vários países e o sistema capitalista mundial tornase uma relação de dependência a partir do momento em que algumas nações podem expandir-se por conta própria, enquanto outras, estando numa situação de dependência, só o podem fazê-lo limitadamente, em parte como reflexo da expansão da economia mundial (ALMEIDA FILHO, 2005; DOS SANTOS 1970; 2015).

Em termos teóricos, a TD constitui uma tentativa de entender a reprodução do sistema capitalista na periferia, enquanto um modo de produção que cria e amplia diferenciações em termos políticos, econômicos e sociais entre países e regiões internas a cada país, a partir do processo de desenvolvimento desigual e combinado. Esta teoria aparece, portanto, como uma crítica à tradicional visão do subdesenvolvimento como uma ausência de desenvolvimento ou teoria da modernização, que argumentava que o atraso dos países subdesenvolvidos era explicado pelos obstáculos que neles existiam a seu pleno desenvolvimento ou modernização (DOS SANTOS, 2000; AMARAL, 2012)5.

Diferente do desenvolvimentismo, a TD não condiciona subdesenvolvimento e desenvolvimento como etapas de um processo evolutivo, e sim como realidades que, ainda que estruturalmente vinculadas, são distintas e contrapostas, e por isso se fez necessário superar a compreensão de subdesenvolvimento enquanto uma situação de desenvolvimento pré-industrial. Dito isso, o subdesenvolvimento passa a ser compreendido como produto do desenvolvimento

\footnotetext{
${ }^{4}$ As chamadas teorias da dependência são formuladas entre os anos de 1964 e 1973, e mantém sua influência até fins dos 1970,quando se consolida no meio acadêmico latino-americano, com o apoio dos Estados Unidos, a liderança do pensamento liberal-conservador do processo de redemocratização da América Latina (MARTINS, 2011).

${ }^{5}$ As teses de convergência estão principalmente vinculadas a chamada teoria da modernização de Rostow, segundo o qual o caminho para o desenvolvimento era universal, seguindo sucessivas fases. Como observa Martins (2011, p. 224) "a pretensão formulada pela teoria da modernização de um mesmo caminho de desenvolvimento para as diversas sociedades nacionais revela-se absurda". Entretanto o "etapismo" de Rostow terá profunda influência sobre o pensamento econômico latino-americano e, principalmente, sobre as ações "desenvolvimentistas" dos governos militares da década de 1970.
} 
capitalista mundial e das específicas condições de cada formação social e econômica nacional, sendo por este motivo, forma específica de capitalismo (DUARTE \& GRACIOLLI, 2007; MARTINS, 2011).

Pode-se, em termos gerais, seguindo Blomstrom e Hettne (1990), resumir as ideias centrais defendidas pela TD em quatro pontos específicos: i) o primeiro seria que a visão de subdesenvolvimento está intimamente ligada com a expansão dos países industrializados, o que implica a percepção de que subdesenvolvimento e desenvolvimento não sejam formas contraditórias e sim complementares; ii) o segundo refere-se a dialética da totalidade capitalista: desenvolvimento e subdesenvolvimento são aspectos distintos do mesmo processo universal; iii) o terceiro refere-se ao fato de que o subdesenvolvimento não pode ser considerado como um ponto de partida de um processo "evolucionista", ou seja, subdesenvolvimento gera mais subdesenvolvimento; iv) e por fim, o fato de a dependência não ser somente fenômeno externo, mas também e principalmente, uma condição da dinâmica e da estrutura interna de cada formação econômica nacional e regional. Estes pontos justificam a ideia de que a produção capitalista é permanentemente desigual e excludente, e por conta disso possui características que reproduzem, ao mesmo tempo e na mesma medida, desenvolvimento e subdesenvolvimento em distintas regiões. Vale acrescer que a dependência se relaciona a intensa vulnerabilidade externa dos países periféricos frente aos centrais, sendo ainda possível identificar a condição dependente de um país a partir de seus níveis de vulnerabilidade externa e da forma como as diferentes regiões se integram nacionalmente, marcada por uma característica da presença de um ou mais polos nacionais centrais e o restante regiões subordinadas e periféricas ao polo nacional principal.

Em termos estritamente econômicos entende-se que as relações estruturais entre nações estavam para além do campo das relações mercantis de trocas internacionais - como acreditavam os teóricos desenvolvimentistas - se configurando também no movimento internacional de capitais, em especial na forma dos investimentos estrangeiros diretos (IED) e na dependência tecnológica. Esses dois fatores seriam parte manifestas do imperialismo, que ao permear toda a economia e sociedade dependentes, condiciona suas estruturas socioeconômicas, integrando de forma subordinada a economia brasileira à economia internacional. (DOS SANTOS, 1970, 2015; DUARTE \& GRACIOLLI, 2007; MARINI, 2000).

O capitalismo dependente, ou seja, a forma especifica como o capitalismo se desenvolve nas economias periféricas está baseada naquilo que Marini $(2000,2005)$ e Dos Santos ([1970] 2011) denominam de "superexploração do trabalho", manifestação própria de produção e apropriação de mais-valia sustentada em mecanismos de exploração intensiva da força de trabalho ou em formas de rebaixamento do valor da força de trabalho possibilitando superlucro e 
transferência de riqueza de uma economia nacional periférica para as economias centrais do capitalismo global. Pode-se acrescer a percepção exposta, outra condição que parece se tornar central na atual forma de expressão das relações de subordinação econômica internacional; a espoliação dos recursos naturais enquanto forma daquilo que Harvey $(2005$, p. 115) denomina de "acumulação via espoliação", uma forma de concentração de riqueza por intensiva degradação dos recursos naturais, o que é bastante visível no padrão de desenvolvimento que se dá na Amazônia brasileira, especialmente no estado do Pará.

De maneira geral, a teoria da dependência significou um salto na compreensão da realidade brasileira e latino-americana, uma vez que a problemática do atraso e do subdesenvolvimento era percebida tanto pelos teóricos da modernização quanto pelos cepalinos, sob a ótica do nacionalismo metodológico ${ }^{6}$, que vê a economia mundial como um agregado de economias nacionais independentes que se relacionam entre si, principalmente por meio do comércio. Tal retificação não implicava um choque com estruturas internacionais, mas sim com grupos sociais e mentalidades internas (MARTINS, 2011, p.229). As soluções para isto variavam tal como 0 diagnóstico, mas tinha em comum o fato de que significavam o desenvolvimento do poder de decisão nacional a partir do estabelecimento de bases industriais próprias que, paulatinamente, conduziria à convergência com os padrões econômicos, políticos e sociais dos países centrais.

Como notam Martins (2011, p.230) e Gilpin (2002, p. 311) a reprodução da dependência é parcialmente resultante de uma divisão internacional do trabalho hierarquizada, isto significava dizer que, há uma estrutura econômica social, política e ideológica, simultaneamente nacional e internacional, algo específico da economia mundial capitalista, onde o subdesenvolvimento se estabelece não como uma espécie de não desenvolvimento, mas como o desenvolvimento de uma trajetória subordinada dentro da economia mundial. O que define estruturalmente a dependência, portanto, é o grau de subordinação e de limite tecnológico que estabelece barreiras a expansão autônoma e geral do departamento I da economia7 (setor produtor de bens de capital), permanecendo atrofiado e subordinado ao exterior.

\footnotetext{
6 Termo usado primeiramente por Hermínio Martins em seu artigo Time, Theory and Sociology (1974). Na fundamentação teórica do nacionalismo metodológico, a nação/país é vista como uma "unidade autossuficiente e inserida em um ambiente internacional indiferenciado" (MEDEIROS, 2010). Ou ainda, seria uma abordagem em que "as trajetórias dos países são explicadas essencialmente por estratégias implementadas por seus estados nacionais". (MEDEIROS, 2010). Ver mais em Vieira (2013).

7 Marx categorizou a economia em dois departamentos onde Departamento I corresponde aos bens de capital e Departamento II corresponde aos bens de consumo. A relação entre departamentos econômicos procede a maior ou menor troca entre insumos tecnológicos no interior das próprias fronteiras nacionais, de tal maneira que a presença de do Departamento I com elevado grau de autonomia e definição de engenharia e estrutura reprodutiva garante a economia em questão maior grau de poder de decisão econômico e reduz expressivamente sua vulnerabilidade externa, conferir Mandel (1985), Harvey (1990) e Gonçalves (2005).
} 


\section{DESENVOLVIMENTO DEPENDENTE REGIONAL, INDICADORES DE VULNERABILIDADE EXTERNA E ESPAÇO PERIFÉRICO NACIONAL}

Vulnerabilidade externa, segundo Gonçalves (2005) é a baixa capacidade de resistência das economias nacionais a choques e desequilibrios externos. Neste sentido, uma economia reduz sua capacidade de resistência frente a fatores externos quando possui elevada dependência de capitais estrangeiros ou fluxos econômicos sob pequena capacidade de controle local, ou fragilidade financeira externa.

É possível ainda, definir vulnerabilidade externa a partir do grau de competitividade de uma economia, que pode ser explicado tanto por fatores de caráter conjuntural, que oscilam no curto prazo, quanto por fatores de caráter estrutural, cujas alterações verificam-se no longo prazo. Nesse sentido, fatores de caráter conjuntural estão associados à política econômica doméstica, bem como elementos exógenos às decisões de políticas econômicas, como o crescimento da economia mundial ou políticas comerciais de parceiros no comércio exterior. Já os fatores estruturais, por sua vez, estão associados à taxa de progresso tecnológico e de produtividade alcançada pela economia, estrutura institucional do mercado de trabalho e do sistema de financiamento, entre outros (JAYME Jr e RESENDE, 2009).

Tal fragilidade decorre, ainda, do grau de abertura, bem como das formas de abertura, que são incompatíveis com a realidade, como por exemplo, da economia brasileira. Entretanto, a questão da vulnerabilidade externa não se restringe à capacidade de resistência, uma vez que existem os problemas, segundo Gonçalves (1999), das opções e dos custos de se contrapor à influência das variáveis externas. Desta forma, para Jones (1995), a vulnerabilidade tem duas dimensões igualmente importantes: uma envolvendo as opções de respostas com os instrumentos de política disponíveis, e outra que incorpora os custos de enfrentamento ou de ajuste frente aos eventos externos (GONÇALVES, 1996).

A vulnerabilidade externa engloba os custos negativos da resistência aos efeitos negativos da volatilidade dos fluxos financeiros, do investimento e do comércio internacionais. Esta resistência é geralmente exercida com o uso de políticas macroeconômicas tradicionais como as políticas monetária, cambial e fiscal. Agindo de outra forma, os governos podem usar tanto controles diretos sobre fluxos de capital, como a política comercial para enfrentar os problemas criados pela volatilidade dos fluxos internacionais.

A vulnerabilidade externa se manifesta também quando o sistema financeiro doméstico fica com ativos e passivos denominados em moeda estrangeira. Dessa forma, aumenta-se a 
fragilidade do sistema financeiro nacional que, além das mudanças internas, passa a sofrer a influência e o impacto de mudanças, por vezes, abruptas no investimento internacional e torna-se mais sensível às alterações da taxa de câmbio.

Em termos de relações econômicas internacionais, a vulnerabilidade externa em termos econômicos poderá se manifestar nas esferas financeira, comercial, tecnológica e produtivo-real (GONÇALVES, 2005). Na esfera financeira envolve os fluxos de capitais internacionais na forma de investimentos financeiros, empréstimos e financiamentos (Gonçalves, 2005, p.18). Na esfera comercial envolve "as relações, os processos e as estruturas próprias do sistema mundial de comércio de bens e serviços" (Gonçalves, 2005, p.17). Na esfera tecnológica diz respeito à transferência internacional de direitos de propriedade industrial e know how. Por último, porém, central ao nível produtivo-real está relacionada à atuação de empresas transnacionais e os investimentos externos diretos.

Assim, a vulnerabilidade externa é tão maior quanto menor for o conjunto de opções de políticas de ajuste macroeconômico, e quanto maiores os custos do processo de ajuste. Ou seja, a vulnerabilidade externa varia inversamente com as opções de ajuste e diretamente com os custos do ajuste, evoluindo para tornar-se vulnerabilidade estrutural. Vale observar, ainda, que um dos aspectos pouco referenciados no debate sobre a vulnerabilidade externa consiste na sua identificação com as características de dependência nacional e de acomodação das economias regionais àquele processo ou estabelecimento de padrões de economias periféricas regionais. Assim, como se buscará mostrar, pode-se evidenciar um fator de vulnerabilidade externa regional, tratando-se da maior ou menor capacidade que certa região ou local subnacional tem de influenciar positiva ou negativamente no desempenho do setor externo nacional, por outro a maior ou menor interação entre as condições de desenvolvimento local e o grau de internacionalização dessa economia regional (TRINDADE \& OLIVEIRA, 2011, 2014, 2017).

Vale notar que uma das trajetórias relevantes das economias dependentes combina condições externas favoráveis à produção e exportação de bens primários, aliado a uma relativa expansão do mercado interno absorvedor de bens tecnicamente de maior valor agregado, condicionantes que possibilitam "expansão para capacidade de importar dando maior flexibilidade ao setor industrial, além de aproveitar recursos abundantes no setor primário" (TAVARES, 2010, p. 123). Contudo, os limites estruturais de não modificação do padrão industrial necessariamente levarão ao esgotamento dessa restringida capacidade de financiamento possibilitada pelo arranque chinês na atual conjuntura.

Como mostra Martins (2011, p. 270) o Brasil e a América Latina podem se encontrar frente a uma crítica encruzilhada, onde a crise da economia hegemônica estadunidense pode arrastar 
essas formações econômicas a um mero papel de periferia de um "hegemón decadente". Por outro, a forte demanda internacional de bens primários ensejados pela China expõe de forma contraditória a possibilidade de ganhos momentâneos capazes de acomodar crises de balança de pagamentos, porém somente postergando possíveis agravamentos na vulnerabilidade externa dessas economias. A situação específica de certas regiões, especialmente a Amazônia e o Pará, são bastante sintomáticas de um quadro grave de subordinação da sua base produtiva aos canais de comércio exterior centrados no fornecimento de bens primários ou semi-processados. Deste modo, interessa a este estudo finalizar a análise dando conta de indicadores de vulnerabilidade regional, o que possibilita a visualização das condições de desenvolvimento periférico do estado do Pará na atual dinâmica de desenvolvimento brasileiro.

\section{INTERAÇÃO ENTRE DEPENDENCIA E OS ASPECTOS DE VULNERABILIDADE REGIONAL: UMA PRIMEIRA APROXIMAÇÃO MEDIANTE INDICADORES}

O comércio internacional e as esferas de trocas e fluxos de capital, mercadorias e tecnologias no espaço geográfico global e regional podem ser classificados como o movimento mais específico e apropriadamente complexo da dinâmica capitalista, mesmo em termos nacionais. A medição e determinação dos movimentos de três fluxos centrais: produtivo/tecnológico; comercial e financeiro define, segundo os aportes teóricos utilizados, parcela importante do grau de maior ou menor subordinação e interdependência das formações econômicas nacionais e regionais ao poder hegemônico dos centros dinâmicos do capital, inclusive em termos da configuração nacional8.

A Figura 1 ilustra as esferas de interação centrais da Economia Política Internacional (conforme Gonçalves, 2005) e a dinâmica cíclica de acumulação proposta por Marx (1987) e interpretada por Arrighi (1996, p. 8-9), podendo ser, na nossa percepção, encarada como forma de expressão também da expansão econômica regional. Vale ressaltar que a esfera financeira assume preponderância em momentos críticos do desenvolvimento capitalista, impondo seu perfil anômalo ao restante do sistema, sendo que conforme esta interpretação as expansões financeiras

\footnotetext{
8 Tavares \& Gomes (1998) destacam a divisão regional do trabalho como um fator essencial para o crescimento das exportações intra-regionais nos anos 90 . Conforme esses autores, a maior abertura comercial promovida pelos países latino americanos nos anos 90 , sustentada na valorização cambial e na liberalização tarifária e não tarifária, facilitou a divisão regional do trabalho das filiais de empresas estrangeiras na região. De um lado, aumentou a competitividade das exportações norte-americanas, tornando o fluxo de comércio, até então deficitário, superavitário para os EUA. De outro, ao reduzir os custos de transação intra-região, também ampliou "as escalas de mercado para as operações das filiais de empresas transnacionais localizadas na América Latina e modificaram as vantagens comparativas estáticas entre países e atividades, expandindo, em consequência, também as possibilidades de intercâmbio nos níveis regional e sub-regional, ainda que, em muitos casos, às custas da desorganização da produção interna nos setores imediatamente afetados pela perda de competitividade" (item III, pp. 8)
} 
constituem "situação em que o investimento monetário na expansão do comércio e da produção não mais atende, com tanta eficiência quanto às negociações puramente financeiras, ao objetivo de aumentar o fluxo monetário que vai para a camada capitalista".

\section{Figura 1: Esferas de Interação Econômica na EPI com fase de predomínio financeiro}

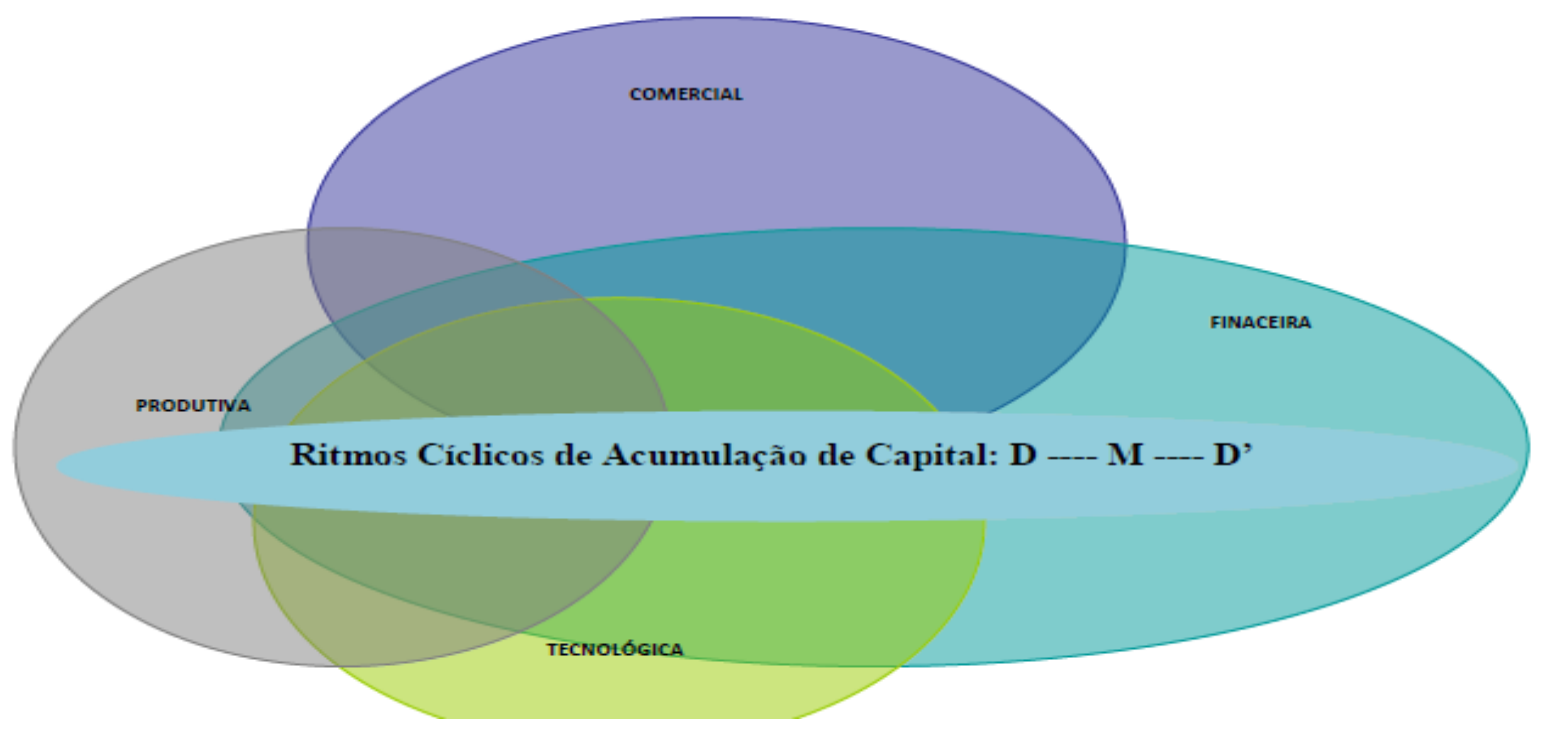

Fonte: TRINDADE E OLIVEIRA (2014). Disponível em: https://goo.gl/PsWnfQ, último acesso em 23/03/2018.

Vale destacar que, conforme Gonçalves (2005), os seguintes condicionantes de análise geral são necessários ao entendimento mais amplo das relações econômicas internacionais, com particular influência no caso brasileiro:

(1) A restrição ao comércio externo pode gerar um significativo processo de substituição de importações. Esse processo é um fator de expansão da demanda agregada e, portanto, tem efeitos diretos sobre a geração de emprego e renda para o trabalhador.

(2) $O$ argumento da substituição de importações enquadra-se no argumento mais geral a respeito da indústria nascente. A proteção permite o início da produção doméstica que, ao longo do tempo, poderá se beneficiar de economias de escala e de aprendizado.

(3) Vale observar que autores institucionalistas, entre estes principalmente Chang (2003) discorda dessa temporalidade limitada das condições e processo de substituição de importações, observa, por exemplo, que estratégias de "cath-up" foram aplicadas enquanto políticas industriais, comerciais e tecnológicas em quase todos os países desenvolvidos quase que em contraposição as políticas e proposições ortodoxas.

(4) Gonçalves (2004, 2005), contudo observa que "os novos modelos de comércio internacional apresentam argumentos a respeito da sequência de estratégias e de políticas comerciais estratégicas", ele denota que os modelos de imperfeições de mercado, economias de escala e 
diferenciação de produto podem indicar que a substituição de importações (inward-looking strategy) seja condição inicial necessária para a subsequente fase de maior abertura para 0 exterior via exportações (outward-looking strategy).

(5) A internacionalização produtiva tem como base a busca de maior rentabilidade por parte do agente empresarial, estabelecendo mecanismos de busca de lucro nos diversos mercados nacionais. Há três formas básicas de internacionalização da produção: comércio, investimento externo direto e relações contratuais.

i) A forma comercial, que define o grau de abertura de uma economia nacional ${ }^{9}$, parte de uma base local produtiva e busca explorar demanda internacional desde seu limite de diferenciação técnica e diversidade produtiva. Assim, quanto maior a capacidade tecnológica maior o poder da base exportadora de uma economia. 0 comércio exterior pode ter impacto sobre a geração de renda e de emprego por meio do processo de afrouxamento da restrição de balanço de pagamentos e, finalmente, a expansão do comércio exterior, tanto das exportações quanto das importações, pode ter impacto favorável sobre as finanças públicas. A tributação sobre as exportações e importações amplia a base fiscal. Estes recursos fiscais podem ser usados para expandir os gastos públicos e, portanto, gerar renda e emprego na economia.

ii) O Investimento externo Direto (IED) implica no deslocamento de capitais, na forma de estrutura empresarial, com vistas a se beneficiar de vantagens locacionais, ou seja, "as variáveis que são próprias a cada mercado", sendo centrais àquelas referentes aos preços relativos de meios de produção e força de trabalho em cada base geográfica produtiva, assim como dinâmicas internas próprias como capacidade de geração e desenvolvimento tecnológico, além da infraestrutura produtiva. Gonçalves (2005, p. 113) observa que os fatores locacionais de maior relevância são: tamanho efetivo e potencial da demanda nacional; institucionalidade e estabilidade do regramento econômico, assim como definições macroeconômicas, tais como políticas tributárias, tarifárias e cambiais.

iii) As relações contratuais estão ligadas as transações internacionais de serviços ${ }^{10}$, de tal maneira que o produtor internacional de serviços permite que algum produtor do país hospedeiro produza o serviço em questão, o exemplo das franquias internacionais são plenamente aplicáveis,

\footnotetext{
${ }^{9} O$ grau de abertura é definido pela relação entre 0 agregado de exportações $(X)$ e importações $(M)$ em relação ao produto interno bruto (PIB): $([(X+M) / P I B] \%)$.

${ }^{10}$ As teorias clássicas e convencionais do comércio internacional se concentram quase exclusivamente no comércio de bens, isso em função da complexidade de se tratar a forma mercadoria "serviço". O serviço é em geral imaterial, intangível e não armazenável (GONÇALVES, 2005, p. 114), daí a necessidade de se tratar as trocas de serviços a partir de relações contratuais que especifiquem as bases de transferência de valores.
} 
considerando, inclusive o uso de bandeiras ou marcas em redes de alimentação, vestuário ou serviços de comunicação ou de aprendizagem (ensino de línguas, por exemplo).

O espaço de interação das condições de vulnerabilidade e dependência inter-regional é amplo, o que se pode comprovar considerando um conjunto de indicadores que, em conformidade a Gonçalves (2005, p.131), denotam o grau de vulnerabilidade regional.

O primeiro campo de análise será a comparação ao nível da federação do indicador referente à esfera comercial. A esfera comercial dimensiona o papel de uma determinada unidade federativa nas condições de relação do país com o sistema de trocas internacionais e grau de diversificação econômica regional. Vale observar, que na medida em que as unidades federativas atuam em um sistema fechado, podem-se ter unidades que detenham fortes saldos comerciais (em termos de balanço), porém com baixa capacidade de influência federativa e de padrões de qualidade de vida de suas populações.

Assim, o grau de diversificação econômica regional é estimado considerando os seguintes parâmetros qualitativos: características tecnológicas e diversidade da pauta de exportação e características tecnológicas e diversidade da pauta de importação. A unidade federativa que apresenta pauta de exportação centrada em poucos bens e de baixa intensidade tecnológica; assim como apresenta importação de bens de elevada ou média intensidade tecnológica, independente do grau de diversidade ou muito vinculado ao padrão de produção; essas unidades são de pequena diversificação econômica e forte candidatas a serem somente periferias regionais exportadoras de recursos naturais e, portanto, com baixa capacidade de poder federativo, por mais que detenham indicadores elevados, por assim dizer transferem poder de troca para a federação e para as demais unidades subnacionais, reforçando as relações de poder interno desde o centro mais diversificado até as unidades periféricas mais dependentes.

Apesar de Gonçalves (2005) ter elaborado tal metodologia com o intuito de medir a vulnerabilidade externa entre países, neste trabalho, o mesmo se fará, para o nível regional e estadual. Posto isto, a esfera comercial, já mencionada no parágrafo acima, em sua magnitude é composta por dois índices, denominados de índice de concentração das exportações (ICE) e outro chamado de indicador de competitividade (IC). O primeiro é resultado da razão entre a exportação estadual pelo produto interno bruto (PIB) estadual, enquanto que o segundo é obtido pela razão entre a subtração da exportação e importação e a soma da exportação e importação, a base de dados utilizada foi a disponível para o ano de 2005 do Censo de Capitais Estrangeiros do Banco Central do Brasil (BACEN, 2005) ${ }^{11}$. 11 Infelizmente o Censo de Capitais Estrangeiros não teve na sua continuidade o mesmo detalhamento deste de 2005
que possibilitou a construção dos índices de vulnerabilidade estadual, conferir https://goo.gl/wCJsX7. 
A significância econômica do indicador é qualificada pelo grau de diversificação econômica, por exemplo, no caso do estado do Pará, observarmos que o principal produto da pauta de exportação é o minério de ferro, que em 2010 representou mais de $50 \%$ de tudo que foi exportado pelo estado (ver TRINDADE e OLIVEIRA, 2011, p.6) e mais de 30\% da exportação nacional do produto. $\mathrm{O}$ aumento da demanda do produto no mercado internacional (mesmo com a elevação substancial do preço), principalmente da China, vem aumentando a exportação do produto. 0 citado país asiático, por exemplo, foi o destino de $50 \%$ de todo o minério de ferro produzido no Pará em 2010.

Os indicadores devem ser interpretados ou qualificados considerando tanto a dimensão ordinal dos mesmos (são decrescentes), quanto o poder de cardinalidade dos mesmos, ou seja, a diversidade econômica da unidade federativa em questão. No caso dos estados amazônicos, este indicador denota o grau de fragilidade que unidades como Pará e Mato Grosso detém como mostra a Tabela 1, o que se reforça pela problemática característica da base exportadora dos mesmos. É importante frisar que a exportação de boi vivo que vem crescendo recentemente e chegou a quase 5\% das exportações do estado em 2010. O Pará é praticamente o único exportador do referido produto, com quase $98 \%$ da exportação de boi vivo do Brasil.

Tabela 1 - Índice da Esfera Comercial - Ano 2005

\begin{tabular}{cccc}
\hline UF & $\begin{array}{c}\text { Índice de Concentração das } \\
\text { Exportações }\end{array}$ & $\begin{array}{cc}\text { Indicador de Competitividade } \\
\text { PA }\end{array} 1^{\text {Média }}$ \\
\hline MT & 54,0 & 98,3 & 99,13 \\
ES & 93,7 & 100,0 & 77,1 \\
SC & 48,9 & 57,1 & 75,4 \\
MG & 52,0 & 80,3 & 64,6 \\
RS & 55,1 & 76,8 & 64,4 \\
MA & 49,7 & 64,0 & 59,6 \\
AL & 22,5 & 66,2 & 57,9 \\
PR & 49,6 & 84,4 & 53,4 \\
PI & 8,1 & 52,5 & 51,0 \\
RN & 12,8 & 86,9 & 47,5 \\
MS & 17,4 & 73,9 & 43,3 \\
SP & 36,4 & 66,5 & 42,0 \\
BA & 32,6 & 47,2 & 41,8 \\
GO & 16,2 & 50,3 & 41,5 \\
\hline
\end{tabular}

Fonte: BACEN - Censo de Capitais Estrangeiros 2005, Tabela IV- Balanço Consolidado por Unidade da Federação, disponivel em https://goo.gl/wCJsX7; STN (Secretaria do Tesouro Nacional)- Receita e Despesa - Balanço 2005, disponivel em: https://goo.gl/KjpKX5.

Considerado o segundo maior exportador da Amazônia e terceiro do país em termos de saldo comercial, o Mato Grosso apresentou saldo comercial em 2010 de US\$ 7,4 bilhões, sendo 
cerca US $\$ 8,4$ bilhões de exportação e quase US\$ 1 bilhão em importação. Suas exportações são compostas por mais de $90 \%$ de produtos básicos; destes, a soja é o principal (quase $40 \%$ ). Os três primeiros da lista - soja, bagaço e outros resíduos sólidos e milho - somam cerca de $73 \%$ da pauta de exportação desta unidade federativa. Esta configuração dos estados do Pará e Mato Grosso pode vir a explicar o comportamento dos índices que compõem a esfera comercial.

O setor exportador Mato-grossense apresentou evolução surpreendente nos anos recentes. Isto se evidencia pelo fato de que nos anos de 1998 a 2010, as exportações cresceram ano após ano. Enquanto no primeiro ano o estado exportou US\$ 652 milhões, o valor em 2010 atingiu US\$ 8,4 bilhões, o que dá mais de $1000 \%$ de variação. No que diz respeita à soja, a China é o principal destino da produção no estado. Dos US\$ 3,2 bilhões exportados em soja em 2010, cerca de US\$ 2 bilhões foram de vendas para o país asiático (correspondeu a 5,4 milhões de toneladas do produto).

A análise qualificada dos indicadores dos dois primeiros estados ranqueada demonstra sensível diferença entre eles. Por mais que a média seja próxima $(99,13$ e 77,21$)$, porém a economia mato-grossense demonstra menor dependência em relação ao setor externo, por mais que seja muito expressivo. Por outro, vale denotar a diferença entre a economia paraense e a mineira, ambas com grande relevância do setor mineral. No caso de Minas Gerais a maior diversidade produtiva e composição diferenciada de exportações e importações ficam evidente nos menores indicadores (ICE e ICC), por mais que o ICE ainda seja muito expressivo em função da expressiva importância da pauta exportadora mineral naquele estado.

O segundo campo de análise é composto pela comparação qualificada, novamente, ao nível nacional dos indicadores referentes à esfera produtiva. Ou seja, a dimensão da atuação das empresas transnacionais e o investimento direto feito pelas mesmas, a partir de componentes de sua composição financeira, dispostos na tabela abaixo.

A esfera produtiva em sua magnitude é composta por quatro indicadores (tabela 2), os quais denominamos de índice 1, 2, 3 e 4 . 0 primeiro é resultado da razão entre Receita operacional bruta de empresas estrangeiras no Estado e o PIB do Estado, o segundo da razão entre a Remessa de lucros e dividendos de empresas estrangeiras no Estado e o Resultado operacional bruto de empresas estrangeiras no Estado, o terceiro a razão entre os Royalties pagos a não residentes por empresas estrangeiras no Estado e o Resultado operacional bruto de empresas estrangeiras no Pará, e por fim o quarto se constitui na razão entre a Retenção Tributária das Empresas Estrangeiras dos Estados e o PIB do Estado. 
Tabela 2- Índice da Esfera Produtiva - Ano 2005

\begin{tabular}{cccccc}
\hline UF & Indicador $\mathbf{1}$ & Indicador $\mathbf{2}$ & Indicador $\mathbf{3}$ & Indicador $\mathbf{4}$ & Média \\
\hline AM & 5,89 & 17,74 & 100,00 & 17,68 & 35,32 \\
DF & 2,54 & 100,00 & 30,12 & 0,63 & 33,32 \\
SP & 56,25 & 9,83 & 45,04 & 18,49 & 32,40 \\
RJ & 57,24 & 1,59 & 15,26 & 42,92 & 29,25 \\
RS & 100,00 & 0,82 & 1,01 & 10,01 & 27,96 \\
MG & 28,85 & 14,58 & 58,63 & 9,20 & 27,81 \\
PR & 39,68 & 4,99 & 36,96 & 12,09 & 23,43 \\
BA & 33,24 & 14,99 & 33,00 & 11,10 & 23,08 \\
PA & 4,98 & 44,43 & 20,14 & 0,29 & 17,46 \\
PE & 16,42 & 6,28 & 16,74 & 5,09 & 11,13 \\
GO & 12,27 & 18,16 & 6,57 & 2,55 & 9,89 \\
MT & 26,93 & 4,90 & 0,46 & 3,18 & 8,87 \\
MA & 13,88 & 10,54 & 0,15 & 3,57 & 7,04 \\
CE & 6,45 & 9,26 & 8,60 & 1,98 & 6,57 \\
\hline
\end{tabular}

Fonte: BACEN - Censo de Capitais Estrangeiros 2005, Tabela IV- Balanço Consolidado por Unidade da Federação, disponível em https://goo.gl/wCJsX7; STN (Secretaria do Tesouro Nacional)- Receita e Despesa - Balanço 2005, disponível em: https://goo.gl/KjpKX5.

Na análise dos indicadores referentes á esfera produtiva, a análise deverá inicialmente de considerar cada indicador e sua significância em termos macroeconômicos. Os Estados com maiores indicadores que relacionam as receitas brutas das empresas multinacionais em relação ao PIB devem ser analisados pela maior atratividade econômica e pelas condições especificas de infraestrutura que condicionam a presença capitalista. Assim, o primeiro indicador é sempre maior nas unidades mais desenvolvidas da federação, o que implica numa fragilidade sistêmica, ou seja, as condições de controle macroeconômico nacionais são dependentes das decisões tomadas pelas matrizes dessas empresas, elemento característico das economias dependentes periféricas ou semiperiféricas como tratado no capítulo inicial. O Pará apresenta indicador que é fortemente influenciado pela presença de empresas transnacionais no setor mineral, porém atenuado, de algum modo, pela forte influência que a Companhia Vale exerce, sendo que sua presença e seu caráter "nacional", segundo os registros do Bacen atenuam o perfil da presença do capital internacional.

O terceiro campo a ser analisado, é composto pela comparação, ao nível nacional do indicador referente à esfera monetária/financeira. Ou seja, a dimensão dos investimentos financeiros, empréstimos e financiamentos, refletidos no montante da dívida externa dos Estados, o total do seu patrimônio líquido, e o pagamento de juros a empresas não residentes por parte destas unidades federativas. Os índices compostos por tais variáveis estão dispostos na tabela a seguir (tabela 10). 
A esfera monetária financeira em sua magnitude é composta por três indicadores, os quais denominamos de índices 1, 2, 3. 0 primeiro é resultado da razão Dívida Externa do Estado pelo PIB do Estado, o segundo da razão Dívida externa de empresas estrangeiras no Estado e 0 Patrimônio líquido de empresas estrangeiras no Estado, o terceiro a razão entre Pagamento de juros por empresas estrangeiras no Estado e o Resultado operacional bruto de empresas estrangeiras no Estado.

Tabela 3 - Índice da Esfera Financeira - Ano 2005

\begin{tabular}{ccccc}
\hline UF & Indicador $\mathbf{1}$ & Indicador 2 & Indicador 3 & Média \\
\hline PA & 35,80 & 6,10 & 100,00 & 47,30 \\
BA & 100,00 & 25,11 & 9,86 & 44,99 \\
PR & 87,44 & 25,01 & 8,88 & 40,44 \\
AM & 66,65 & 24,36 & 3,21 & 31,41 \\
MA & 71,65 & 10,34 & 9,01 & 30,33 \\
RJ & 25,06 & 60,18 & 4,35 & 29,86 \\
MT & 3,87 & 41,16 & 33,32 & 26,12 \\
MG & 36,55 & 16,27 & 14,74 & 22,52 \\
RS & 45,12 & 18,67 & 0,87 & 21,55 \\
SP & 10,17 & 41,19 & 8,41 & 19,92 \\
PE & 0,00 & 15,39 & 4,95 & 6,78 \\
GO & 8,25 & 6,02 & 0,82 & 5,03 \\
CE & 0,00 & 8,25 & 6,56 & 4,94 \\
DF & 0,17 & 0,29 & 10,18 & 3,55 \\
\hline
\end{tabular}

Fonte: BACEN - Censo de Capitais Estrangeiros 2005, Tabela IV- Balanço Consolidado por Unidade da Federação, disponível em https://goo.gl/wCJsX7; STN (Secretaria do Tesouro Nacional) - Receita e Despesa - Balanço 2005, disponível em: https://goo.gl//KjpKX5.

Quanto a análise dos indicadores da esfera financeira, observa-se que as unidades federativas que possuem índice de vulnerabilidade financeira mais elevada em relação aos Estados inseridos na dinâmica nacional de acumulação, são Mato Grosso, Rio Grande do Norte e Tocantins. Novamente, nos deparamos com a presença de dois Estados componente da Região Norte e um da Região Nordeste, uma vez que como apresentado no terceiro capitulo deste trabalho acerca dos desequilíbrios regionais do país, tais regiões figuram, nos termos da Teoria da Dependência, como as regiões mais dependentes da dinâmica nacional, seja pela sua composição histórica ou pela localização regional (periferia nacional) em relação ao centro dinamizador do país, no caso São Paulo.

Posto isto, pode-se calcular o Índice de Vulnerabilidade Externa dos Estados Brasileiros (IVEUF), que é um índice obtido através da média simples de três outros índices: vulnerabilidade comercial (IVCO), vulnerabilidade produtivo/tecnológica (IVPT) e vulnerabilidade monetáriofinanceira (IVMF). Cada um destes índices expressa uma esfera específica do sistema econômico 
internacional. E cada um desses índices, por seu turno, é a média simples de índices correspondentes a indicadores (coeficientes) específicos de vulnerabilidade econômica externa (Ver tabela 5).

Tabela 4 - Índices: Estatística Descritiva - Ano 2005

\begin{tabular}{c|c|c|c|c|c|c}
\hline ÍNDICES & Média & Mediana & $\begin{array}{c}\text { Desvio- } \\
\text { Padrão }\end{array}$ & $\begin{array}{c}\text { Coeficiente } \\
\text { de variação }\end{array}$ & Máximo & Mínimo \\
\hline IVEUF & 32,21 & 31,37 & 9,65 & 29,94 & 49,28 & 14,94 \\
\hline IVCO & 60,75 & 57,54 & 14,87 & 24,48 & 93,34 & 42,49 \\
\hline IVPT & 18,23 & 12,34 & 15,63 & 85,78 & 52,73 & 0,01 \\
\hline IVMF & 17,65 & 16,02 & 11,85 & 67,11 & 49,82 & 1,68 \\
\hline
\end{tabular}

Fonte: BACEN - Censo de Capitais Estrangeiros 2005, Tabela IV- Balanço Consolidado por Unidade da Federação, disponível em https://goo.gl/wCJsX7; STN (Secretaria do Tesouro Nacional)- Receita e Despesa - Balanço 2005, disponivel em: https://goo.gl/KjpKX5.

$\mathrm{Na}$ tabela 4, estão dispostas as estatísticas descritivas dos índices apresentados no decorrer deste capítulo. Tais índices referem-se à uma amostra de 27 estados. O IPP médio é de 18,54, o IVEUF médio é de 32,21 e o IPE médio é de 67,79 (100 menos o IVE). A dispersão relativa, informada pelo coeficiente de variação, é mais elevada no caso do índice de vulnerabilidade externa do que nos casos dos índices de poder potencial e efetivo. Isto demonstra que há uma grande dispersão dada a heterogeneidade no índice de vulnerabilidade externa regional quanto nas três esferas componentes, e que os dados referentes ao poder potencial são mais homogêneos que os referentes ao IVEUF e o IPE.

Nas distintas esferas do sistema econômico internacional, a dispersão relativa é mais elevada no caso da esfera produtivo-tecnológica. De fato, o índice de vulnerabilidade nessa esfera (IVPT) é o que tem maior coeficiente e variação dentre todos outros índices. Isso pode ser resultado da desnacionalização da economia brasileira e de sua crescente concentração de capital provocada pela presença de empresas estrangeiras no país e nas regiões que o compõe. 
Tabela 5-Vulnerabilidade Externa Regional: Esferas Comercial, produtivo-tecnológica e monetário-financeira - Ano 2005

\begin{tabular}{cccccccc}
\hline UF & IVCO & UF & IVPT & UF & IVMF & UF & IVEUF \\
\hline PA & 93,34 & AM & 35,32 & PA & 47,30 & PA & 54,63 \\
MT & 88,38 & DF & 33,32 & BA & 44,99 & PR & 38,29 \\
PR & 75,22 & SP & 32,40 & PR & 40,44 & MG & 38,24 \\
RS & 72,45 & RJ & 29,25 & AM & 31,41 & MT & 37,36 \\
MG & 71,60 & RS & 27,96 & MA & 30,33 & BA & 36,53 \\
BA & 69,71 & MG & 27,81 & RJ & 29,86 & RS & 36,37 \\
AM & 68,79 & PR & 23,43 & MT & 26,12 & MA & 31,76 \\
MA & 66,93 & BA & 23,08 & MG & 22,52 & SP & 31,37 \\
SP & 64,14 & PA & 17,46 & RS & 21,55 & AM & 31,18 \\
GO & 57,54 & PE & 11,13 & SP & 19,92 & RJ & 26,27 \\
RJ & 56,25 & GO & 9,89 & PE & 6,78 & GO & 18,41 \\
CE & 52,06 & MT & 8,87 & GO & 5,03 & CE & 14,04 \\
PE & 49,05 & MA & 7,04 & CE & 4,94 & DF & 12,29 \\
DF & 42,49 & CE & 6,57 & DF & 3,55 & PE & 11,50 \\
\hline
\end{tabular}

Fonte: BACEN - Censo de Capitais Estrangeiros 2005: Tabela IV- Balanço Consolidado por Unidade da Federação; STN (Secretaria do Tesouro Nacional) - Receita e Despesa342 - Balanço 2005

A tabela 5 apresenta uma síntese dos índices de vulnerabilidade externa regional nas esferas comercial, produtivo-tecnológica e monetário-financeira, bem como a média desses índices, que é o nosso índice final de vulnerabilidade externa regional dos Estados Brasileiros (IVEUF). Vale repetir, a amostra inclui 27 Estados. Segundo os dados, o Pará tem IVEUF igual a 54,63, que é o $1^{\circ}$ maior IVEUF dos Estados da amostra. O IVEUF do Pará é significantemente maior do que a média e a mediana nacional, que são de 32,21 e 31,37 respectivamente.

Entre os Estados com maior vulnerabilidade regional externa encontram-se os Estados da Amazônia Legal (Mato Grosso, Amazonas e Pará), do Nordeste (Rio Grande do Norte e Bahia), do Sul (Rio Grande do Sul e Paraná) e Sudeste (Espírito Santo, Minas Gerais e São Paulo). Vale observar que os Estados com maiores índices de vulnerabilidade são componentes da Amazônia Legal, ambos com 54,63 e 37,36 respectivamente, o que reitera o que foi dito neste trabalho em relação aos desequilíbrios regionais do país, sem falar no histórico de dependência da Amazônia em relação aos outros Estados.

Os índices de vulnerabilidade externa, nas distintas esferas das relações econômicas nacionais, permitem a hierarquização das fontes de fragilidade dos Estados. No caso do Pará, os índices de vulnerabilidade externa são: 93,34 na esfera comercial (IVCO); 17,46 na esfera produtivo-real (IVPT); e 47,30 na esfera monetário-financeira (IVMF). O IVPT está abaixo da média e acima da mediana dos Estados da amostra, enquanto que o IVMF está acima da média e da mediana da amostra. 
No que se refere ao IVCO, o Pará tem o maior índice. Ou seja, o Pará apresenta altíssima vulnerabilidade externa na esfera comercial. O IVCO do Pará é 93,34, mais do que o dobro da média nacional $(32,21)$ e da mediana $(31,37)$. Esse resultado expressa, em certa medida, o fato de o Pará ser uma economia na qual as trocas comerciais com o exterior tende a ter uma importância relativamente alta.

Quando se analisa a vulnerabilidade externa na esfera produtivo-tecnológica, a situação do Pará melhora, pois é a ga posição. O IVPT do Pará $(17,46)$ é menor que a média $(32,21)$ e a mediana $(31,37)$ desse indicador para o conjunto de países da amostra. Isto reflete em grande pela presença relativamente pequena de empresas transnacionais na economia paraense. $\mathrm{Na}$ esfera monetário-financeira, a situação de vulnerabilidade externa do Pará é alta. O IVMF do Pará de 47,30, o maior do país.

\section{CONSIDERAÇÕES FINAIS}

O processo de liberalização cambial-financeira, percebido pela economia brasileira na década de 1990, resultou em uma elevada apreciação cambial e, uma maior exposição externa da economia nacional, agravada pela globalização financeira. Além disto, esta conjuntura levou ao aprofundamento da vulnerabilidade externa da economia brasileira e ao enfraquecimento dos elos importantes que o país possuía.

Dentro desse contexto, ao Estado do Pará, contido na dinâmica econômica da economia brasileira, é demandado o papel de Estado detentor da produção e exportação de produtos primários e criador de divisas externas essenciais ao equilíbrio do balanço de pagamentos do país.

O Pará tem seu dinamismo econômico voltado à produção quase que total de uma gama de produtos extrativos-mineral, o que explica a presença de empreendimentos capitalistas, intensivos em capital, responsável pela extração e beneficiamento destes produtos a fim de abastecer o mercado internacional. Vale ressaltar, que o Estado também percebeu a presença de projetos agroindustriais, agropecuários e madeireiros.

A partir da consolidação dos projetos instalados no Estado, somada às características estruturais dos mesmos, é possível notar que o Pará diversificou sua produção, mesmo sem deixar transcender sua principal característica que é ser exportador de matérias-primas. Isto contribuiu para que a balança comercial paraense se apresentasse superavitária de forma permanente e crescente.

O trabalho buscou analisar a inserção da economia paraense no padrão produtivo nacional, a partir do uso de índices de vulnerabilidade econômica regional, utilizando a metodologia referente à vulnerabilidade externa desenvolvida por Goncalves (2005), com diversas adaptações. 
A análise dos índices que compõem a esfera comercial, e dentro dela 0 índice de concentração das exportações e o indicador de competitividade, foi possível notar que os Estados do Pará e Mato Grosso, respectivamente, em primeiro e segundo lugar apresentam maior fragilidade econômica resultante da problemática de sua base exportadora, o que consequentemente, resulta em maior vulnerabilidade econômica, ou seja, maior dependência em relação ao setor externo.

Já a análise dos indicadores que compõem a esfera produtiva, denominados aqui como índices 1, 2, 3 e 4. Nesta esfera os Estados com maiores indicadores que relacionam as receitas brutas das empresas multinacionais em relação ao PIB, devem ser analisados pela maior atratividade econômica e pelas condições específicas de infraestrutura que condicionam a presença capitalista. Neste sentido o Pará apresenta indicador que é fortemente influenciado pela presença de empresas transnacionais no setor mineral, porém atenuado, de algum modo, pela forte influência que a Companhia Vale exerce, sendo que sua presença e seu caráter "nacional", segundo os registros do Bacen atenuam o perfil da presença do capital internacional. Isto demonstra certa fragilidade sistêmica, ou seja, as condições de controle macroeconômico nacionais são dependentes das decisões tomadas pelas matrizes dessas empresas, elemento característico das economias dependentes periféricas ou semiperiféricas.

Posto, isto a análise dos indicadores relacionados com os aspectos teóricos do Aporte da Dependência, mostrou que o Estado do Pará é bastante sintomático de um grave quadro de subordinação de sua base produtiva aos canais de comércio exterior centrados no fornecimento de bens primários ou semi-beneficiados. Os indicadores possibilitaram ainda visualizar as condições de desenvolvimento periférico do estado Pará dentro da atual dinâmica econômica primário-exportadora estabelecida no país.

\section{REFERÊNCIAS BIBLIOGRÁFICAS}

ALMEIDA FILHO, Niemeyer. "O debate atual sobre a dependência". Revista da Sociedade Brasileira de Economia Política, Rio de Janeiro, 2005, v. 16, p. 32-50.

Brasília: IPEA, 2013, 233p.

(org.). Desenvolvimento e dependência: cátedra Ruy Mauro Marini.

AMARAL, M.S. A Investida Neoliberal na América Latina e as Novas Determinações da Dependência. 2006. Dissertação (Mestrado em Economia) - Instituto de Economia, Universidade Federal de Uberlândia, Uberlândia. 2006.

AMARAL, Marisa Silva. Teorias do imperialismo e da dependência: a atualização necessária ante a financeirização do capitalismo. Tese de Doutorado- USP, São Paulo, 2012, 147 p.

AMARAL, Marisa Silva, Neoliberalismo na América Latina e a Nova Fase da Dependência. Campinas, Brasil, 2007. 
AZZONI, Carlos Roberto. Indústria e reversão da polarização no Brasil. 232f. Tese (LivreDocência em Economia) - USP-Departamento de Economia e Administração, São Paulo, 1985.

Concentração regional e dispersão das rendas per capita estaduais: análise a partir de séries históricas de PIB, 1939-1995. Est.econ., São Paulo: USP, 27(2): 341-393, set-dez 1997.

FERREIRA, Dirceu Alves. Competitividade Regional e Reconcentração industrial: o futuro das desigualdades regionais no Brasil. São Paulo: USP/ Nêmesis - www.nemesis.org.br/doc/pibreg1.pdf - capturado em Fevereiro de 2014.

BANCO CENTRAL DO BRASIL. Censo 2006 de Capitais Estrangeiros no País - Ano-base: 2005. Disponível em: https://goo.gl/wCJsX7, último acesso: 23/03/2018.

BRAGUETO, Claudio Roberto, A Desconcentração Industrial no Brasil e as Transformações Industriais no Estado do Paraná. In: BRAGUETO, C.R. O Aglomerado Urbano-Industrial de Londrina: sua constituição e dinâmica industrial. 2007. 265f. Tese (Doutorado em Geografia Humana) - Faculdade de Filosofia, Letras e Ciência Humanas, Universidade de São Paulo, São Paulo.

BRESSER-PEREIRA, Luiz Carlos. De la CEPAL y el ISEB a la Teoría de la Dependencia. Desarrollo Económico, vol. 46, n 183, 2006.

BICHIR, Maíra Machado. 0 subdesenvolvimento econômico da América Latina Sob a perspectiva da Teoria da Dependência. Projeto de pesquisa Fundação de Amparo à Pesquisa do Estado de São Paulo (FAPESP), 2007.

BIELSCHOWSKY, Ricardo. Pensamento Econômico Brasileiro: o ciclo ideológico do desenvolvimentismo. $5^{\text {a }}$. ed. Rio de Janeiro: Contraponto, 2000. 496 p.

BUARQUE, Sérgio $C$. et al. Integração fragmentada e crescimento da fronteira norte. In: AFFONSO, Rui de Britto Álvares; SILVA, Pedro Luiz Barros da (Org.). Desigualdades regionais e desenvolvimento. São Paulo: Fundap/Unesp, 1995. p. 93-123. (Série Federalismo no Brasil).

CARDOSO, F. H. 1976. "Notas sobre o Estado atual dos estudos de dependência", in: SERRA, J. (Org) América Latina. Ensaios de interpretação econômica. Rio de Janeiro: Paz e Terra, 1976.

CARCANHOLO, M. D. Abertura Externa e Liberalização Financeira: Impactos sobre crescimento e distribuição no Brasil dos anos 90. Tese (Doutorado em Economia) - Instituto de Economia, Universidade Federal do Rio de Janeiro, Rio de Janeiro. 2002.

.Abertura e Vulnerabilidade Externa: Restrições Estruturais para 0 Desenvolvimento em uma Economia Periférica. In: XAVIER, C.L. Desenvolvimento Desigual. Uberlândia: Edufu, 2004. cap. 2, p.73 - 110.

FIORI, José Luís. Sistema mundial: império e pauperização para retomar o pensamento crítico latino-americano. In: FIORI, José Luís. (org.) Polarização mundial e crescimento. Rio de Janeiro: Vozes, 2001. p.39-75.

FIORI, José Luís. 0 voo da coruja. Para reler o desenvolvimento brasileiro. Rio de Janeiro: Record, 2003, "Ciclo e Crise", p.101-197.

FURTADO, Celso. Formação Econômica do Brasil. São Paulo: Companhia Editora Nacional, 2002.

GREMAUD, Amaury P. e PIRES, Júlio M. "Metas e Bases" e I Plano Nacional de Desenvolvimento - I PND (1970-1974). In: KON, Anita (org.). Planejamento no Brasil II. São Paulo: Perspectiva, 1999a. 
Gilpin, Robert. A Economia Politica das Relações internacionais. Brasília:UNB, 2002.

GONÇALVES, Reinaldo. Globalização financeira, liberalização cambial e vulnerabilidade externa da economia brasileira. In: BAUMANN, R. (org.). O Brasil e a economia global. Rio de Janeiro: Elsevier, 1996.

Economia Política Internacional: fundamentos teóricos e as relações internacionais do Brasil. Rio de Janeiro: Elsevier, 2005.

GONÇALVES, José Sidnei. Reprimarização ou Desindustrialização da Economia Brasileira: uma leitura a partir das exportações para o período 1997-2010. São Paulo, Instituto de Economia Agrícola de São Paulo -IEA. Análise e Indicadores do Agronegócio, v.6, nº 12, 2011.

GUIMARÃES NETO, Leonardo. Dinâmica Recente das Economias Regionais Brasileiras. Rev. Paraná. Desenvolv. Curitiba, n.86. set/dez,1995,p.123-152.

Desigualdades e políticas regionais no desenvolvimento brasileiro: caminhos e descaminhos. Brasília, Planejamento e Políticas Públicas, IPEA, (15): jun. 1997.

; BRANDÃO, Carlos. A.. A Formação Econômica do Brasil e a questão regional. In: Francisco da Silva Coelho e Rui Guilherme Granziera. (Org.). Celso Furtado e a Formação Econômica do Brasil: Edição comemorativa dos 50 anos de publicação (1959-2009). 1ed. São Paulo: Editora Atlas/Ordem dos Economistas do Brasil, 2009, v. 1, p. 202225.

HUNT, D. Análise da Dependência no Início do Século XXI. In Economia Ensaios, vol. 17/18 (2/1), julho e dezembro, p. 7-18, 2003.

JAYME, F.G.; RESENDE, M. F. C. Crescimento econômico e restrição externa: teoria e a experiência brasileira. In: MICHEL, R.; CARVALHO, L. (Org.). Crescimento Econômico: Setor Externo e Inflação. Rio de Janeiro: Ipea, 2009.

MARINI, Ruy Mauro. Dialética da Dependência (A). In: SADER, E. Dialética da Dependência. $1^{\text {a }}$ edição. Petrópolis: Vozes, 2000. cap. 2, p.105 - 165.

. "Sobre a dialética da dependência". In: TRASPADINI, Roberta; STEDILE,

João Pedro. Ruy Mauro Marini: Vida e Obra. São Paulo: Expressão Popular, 2005.

Memória. In: TRANSPADINI, R. \& STEDILE, J. P.(orgs.). Ruy Mauro Marini:

Vida e obra. São Paulo: Expressão Popular, 2007.

Editorial IAEN, 2012.

El maestro en rojo y negro. Prólogo Patrício Rivas Herrera1 ${ }^{\text {a }}$ ed.— Quito:

MARTINS, Carlos Eduardo. Superexploração do Trabalho e Acumulação de Capital: reflexões teórico-metodológicas para uma economia política da dependência. Revista da Sociedade Brasileira de Economia Política, Rio de Janeiro, n. 5, p. 121-138, dez., 1999.

Ruy Mauro Marini: marco del pensamiento contemporáneo. En

publicación: América Latina, dependencia y globalización. Fundamentos conceptuales Ruy Mauro Marini Bogotá, CLACSO, 2008.

Globalização, Dependência e Neoliberalismo na América

Latina. Boitempo Editorial, $1^{a}$ Edição - 2011, 368 p.

SECRETARIA DO TESOURO NACIONAL. Execução Orçamentária de Estados (1995/2013). Disponível em: https://goo.gl/KjpKX5. 
TRINDADE, J. R, OLIVEIRA, W. Especialização produtiva primária e meio ambiente em período recente na Amazônia. Novos Cadernos NAEA: v. 14, n. 2, p. 283-302, dez. 2011, ISSN 1516-6481. Disponível em: https://goo.gl//yxgP7G.

$$
\text { PADRÃO DE ESPECIALIZAÇÃO PRIMÁRIO }
$$
EXPORTADOR E DINÂMICA DE DEPENDÊNCIA NAS DUAS ÚLTIMAS DÉCADAS NA ECONOMIA BRASILEIRA. In: NETO, Aristides Monteiro (organizador). Política externa, espaço e desenvolvimento. Brasilia: Ipea, 2014. Disponível em: https://goo.g//PsWnfQ.

Padrão de especialização primário--exportador e dinâmica de dependência no período 1990-2010, na economia brasileira. Ensaios FEE, Porto Alegre, v. 37, n. 4, p. 1059-1092, mar. 2017, ISSN 1980-2668. Disponível em: https://goo.gl/5w7rrR.

Recebido em 20 de Outubro de 2018.

Aceito para publicação em 18 de Maio de 2019.

\title{
RESUMO
}

A capacidade de desenvolvimento regional das unidades estaduais brasileiras pode ser tratada conforme o plano teórico da Teoria da Dependência, subtendendo, de um lado, os vínculos de dependência econômica regionais-federativas e, por outro, o grau de vulnerabilidade externa dessas unidades. Este artigo busca tratar a questão da vulnerabilidade externa regional do Estado do Pará relacionando o mesmo com os demais Estados brasileiros, levando em consideração a dinâmica de acumulação de cada unidade federativa, bem como o processo de desenvolvimento regional das mesmas, a partir da análise de índices de vulnerabilidade econômica regional, adaptando a metodologia de Gonçalves (2005) para o ano de 2005. Nesse sentido, a análise dos indicadores relacionados com os aspectos teóricos do Aporte da Dependência, mostrou que 0 Estado do Pará é bastante sintomático de um grave quadro de subordinação de sua base produtiva aos canais de comércio exterior centrados no fornecimento de bens primários ou semibeneficiados.

Palavras- Chave: Teoria da Dependência; Dependência Econômica; Estado do Pará; Vulnerabilidade Externa Regional.

\begin{abstract}
The regional development capacity of the Brazilian state units can be treated according to the theory of Dependency Theory, subtending, on the one hand, regional-federative economic dependency bonds and, on the other hand, the degree of external vulnerability of these units. This article seeks to address the issue of the regional external vulnerability of the State of Pará, linking it with the other Brazilian states, taking into account the dynamics of accumulation of each federative unit, as well as the regional development process of the same, based on the analysis of indicators of regional economic vulnerability, adapting the methodology of Gonçalves (2005) for the year 2005. In this sense, the analysis of the indicators related to the theoretical aspects of the Contribution of the Dependency, showed that the State of Pará is quite symptomatic of a serious from subordination of its productive base to foreign trade channels focused on the supply of primary or semi-benefited goods.
\end{abstract}

Keywords: Theory of Dependency; Economic Dependence; State of Pará; Regional Vulnerability. 